\title{
Longitudinal reading outcomes in response to a book-based, whole class intervention for students from diverse cultural, linguistic and socio-economic backgrounds
}

\author{
Maria Lathouras (D) ${ }^{a}$, Marleen Westerveld (DD ${ }^{\mathrm{a}, \mathrm{b}}$ and David Trembath (D) ${ }^{\mathrm{b}}$

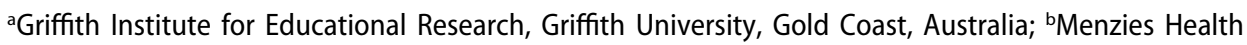 \\ Institute Queensland, Griffith University, Gold Coast, Australia
}

\begin{abstract}
This study aimed to investigate if a universal 24-week oral language and emergent literacy programme delivered to students in the first year of schooling positively impacts reading performance 2-years post intervention. Eighty-nine participants were second grade students from three primary schools in low socio-economic status areas. Using a controlled trial, the original study findings revealed larger gains in oral narrative, receptive vocabulary, and phonological awareness amongst students who received the intervention compared to those who received regular classroom instruction. At follow-up, student reading performance was compared using a standardised reading assessment. There were no differences between students who received the intervention and those who did not. To further investigate these findings, the oral language and emergent literacy skills of "average" and "below average" readers at the end of the first year of schooling were compared to assist in tailoring follow-up interventions. The implications for universal classroom-based programmes are discussed.
\end{abstract}

ARTICLE HISTORY

Received 9 December 2018 Accepted 3 July 2019

\section{Introduction}

International reading results indicate that Australian students continue to achieve low reading level rankings (Mullis, Martin, Foy, \& Drucker, 2012; OECD, 2014). Across Australia, $11 \%$ of year three students are reading at or below national minimum standard on the National Assessment Program - Literacy and Numeracy (Australian Curriculum Assessment and Reporting Authority [ACARA], 2018). However, the level of reading disadvantage is much greater in low socio-economic areas across the state of Queensland, whereby $63 \%$ of students fall below the national minimum benchmark (Parkville Global Advisory, 2014). In Australia, recent efforts have investigated the reading assessment and identification of students at risk (Buckingham, Wheldall, \& BeamanWheldall, 2013; Hempenstall, 2009; Serry, Rose, \& Liamputtong, 2008) including service delivery approaches, frameworks, and interventions (Serry \& Oberklaid, 2015; Wheldall et al., 2016). Enhancing the early literacy skills of students in their first year of school who are diverse in their cultural, linguistic, and economic backgrounds has been a consistent 
theme in these reading-related interventions (Buckingham et al., 2013) with some studies reporting positive immediate results post intervention (e.g. Fielding-Barnsley \& Hay, 2012; (Lennox \& Westerveld, 2014); Mclntosh, Crosbie, Holm, Dodd, \& Thomas, 2007). However, the long-term outcomes of Australian intervention studies are infrequently investigated (e.g. Henning, McIntosh, Arnott, \& Dodd, 2010). The current study aims to examine the longitudinal reading outcomes of students from low socioeconomic areas who participated in a classroom-based, early literacy intervention during the first year of school (i.e. "prep" in Queensland).

\section{The importance of early reading success}

Evidence shows that oral language proficiency prior to school entry is a significant predictor of future reading achievement (Catts, Fey, Zhang, \& Tomblin, 1999; Tunmer, Chapman, \& Prochnow, 2006). Given the significant long-term impact of reading difficulties on students' academic performance, predicting which children are at risk becomes paramount (Murphy, Justice, O'Connell, Pentimonti, \& Kaderavek, 2016), so that appropriate interventions may be provided (Murphy et al., 2016). Consequently, the first year of schooling has emerged as a critical period to target early language and literacy skills of those students who enter school with poor language skills, including those from less economically advantaged backgrounds (O'Connor, Arnott, Mclntosh, \& Dodd, 2009; Torgesen et al., 1999). In fact, there is a considerable body of research supporting the predictive relationship between first year reading results and reading performance in the early primary years (Simmons et al., 2008; Storch \& Whitehurst, 2002; Suggate, Schaughency, McAnally, \& Reese, 2018). Referred to as the Matthew Effect in reading (Stanovich, 1986), poor reading acquisition often results in decreased motivation to read, resulting in less exposure to more advanced text. This substantiates the need for early intervention to close the achievement gap and hence position students for reading success (Fricke, Bowyer-Crane, Haley, Hulme, \& Snowling, 2013; Neumann, 2016; Simmons et al., 2008).

\section{Current early school interventions}

Internationally, there is research evidence regarding the importance of early intervention as a preventative approach to address future reading difficulties (National Institute for Literacy, 2008; National Reading Panel, 2000; Snow, Burns, \& Griffin, 1998). Emergent literacy skills are necessary precursors to formal literacy instruction (National Institute for Literacy, 2008). Emergent literacy skills can be separated into two areas. Code-related skills that are needed for future word-recognition (decoding) which encompass letter knowledge, letter-sound correspondence, phonological awareness, and concepts about print (Snow et al., 1998; Whitehurst \& Lonigan, 1998) and meaning-related skills needed for understanding the decoded words which includes vocabulary, oral narrative ability, and grammar (Tunmer \& Chapman, 2012).

The ultimate aim of learning to read is to read for meaning, also known as reading comprehension. Reading comprehension relies on the complex interplay between decoding and identifying words (i.e. code-related skills), and understanding the meaning 
of the conveyed words (i.e. meaning-related skills) (Gough \& Tunmer, 1986). Gough and Tunmer (1986) termed this relationship as the Simple View of Reading. Despite being innately related, these skills develop independently (Nation, Cocksey, Taylor, \& Bishop, 2010). Catts, Hogan, and Fey (2003) used this framework to categorise the reading comprehension difficulties the students face. For example, "poor comprehenders" are those students who have strong code-related skills but deficits in meaning-related skills. On the other hand, students with strong meaning-related skills but poor code-related skills are termed "developmental dyslexia". Finally, "mixed reading disorders" refer to those students who struggle in both their decoding skills as well as their meaningrelated skills. Students classified under the category of "developmental dyslexia" may in some instances be identified early in their school years, as it is during this time that students learn letter-sound correspondences and start decoding single words (Nation et al., 2010). However, the difficulties that "poor comprehenders" face are often masked by their accurate and fluent decoding skills, particularly during the early school years (Oakhill \& Cain, 2012).

Targeting code- and meaning-related skills of students commencing school who have been identify as at risk have been the focus of numerous studies (Bowyer-Crane et al., 2008; Snow et al., 2014). Results from numerous studies indicate that students from diverse cultural, linguistic, and economic backgrounds who identify as at risk at schoolentry respond positively to early literacy interventions. Our initial study (Lennox, Westerveld, \& Trembath, 2018) showed similar results. More specifically, following a universal 24-week, classroom, book-based intervention, students who participated in the intervention demonstrated significantly larger gains in vocabulary, oral narrative quality (ONQ), and phonological awareness compared to a group of students who received their normal classroom instruction. Despite international research evaluating the long-term effects of early years classroom interventions, there are few Australian studies evaluating whether initial short-terms gains have a significant long-term impact as students move into the middle years of school (Dickinson \& Smith, 1994; Simmons et al., 2008; Suggate, 2016; Zucker, Cabell, Justice, Pentimonti, \& Kaderavek, 2013). For example, Henning et al. (2010) explored whether the positive short-term effects of a classroom-based oral language and phonological awareness programme reported by Mclntosh et al. (2007) were maintained 2-year post intervention. The study sought to determine whether students who received the intervention in the first year of school performed better than controls on measure of vocabulary, grammar, listening, and reading comprehension when they were in their third year of schooling. At follow-up, there were no significant differences between the two groups, on any of the measures, indicating the short-term effects were not maintained. Clearly, more Australian research on students from culturally, linguistically, and economically diverse backgrounds within their first year of formal school is needed to evaluate appropriate intervention programmes and reduce the number of students with later reading difficulties.

\section{Reading performance in the early years of schooling}

Reading proficiency at the end of the first year of school significantly impacts the trajectory of a student's future academic performance (Centre For Public Education, 2015). Second grade reading outcomes mark a critical point in education, as the majority of students at this 
juncture make the transition from learning to read to reading to learn (Simmons et al., 2014). Students who do not successfully transition to reading to learn often experience negative long-term consequences (Hay \& Fielding-Barnsley, 2009). For example, one in six students who do not show adequate reading proficiency in third grade may fail to graduate from high school, which is four times higher than expected for proficient readers (Hernandez, 2011). However, few Australian studies that involve students from diverse cultural and linguistic backgrounds that investigate the longitudinal outcomes of interventions offered in the early school years. This highlights the need for two key pieces of research, (a) longitudinal follow-up of early classroom-based intervention, as well as (b) research to examine factors that impact reading status at the end of grade 2 juncture. The current study reports end of grade 2 reading outcomes of the PrepSTART project, a universal intervention programme delivered during the first year of schooling.

\section{The PrepSTART project}

In our initial study, [published, 2018] we investigated an intervention that targeted year 1 (known as prep in Queensland, Australia) students from diverse cultural, linguistic, and socio-economic backgrounds. The study involved 137 students from three primary schools in Queensland. The Index of Community Socio Educational Advantage (ICSEA) places schools on a four quarter scale with a median value of 1000 and a standard deviation of 100 (ACARA, 2018). The schools involved in the study fell within the bottom quarter percentile, indicating high social disadvantage.

Children in eight classes participated in the intervention, while those in two classes continued to receive their usual classroom instruction (referred to as "business as usual"). The intervention classes received systematic, contextualised book-based whole class intervention targeting the code-based skills of phonological awareness as well as the meaning related skills of vocabulary and oral narrative ability (Justice et al., 2010; National Reading Panel, 2000; Suggate et al., 2018). The programme ran for 24-weeks, each week consisting of four, 1-hour sessions, comprised of a whole class 30-min session followed by a small group 30-min session. The performance of students in the intervention group showed a greater statistically significant improvement than their business as usual peers on ONQ, receptive vocabulary, and phonological awareness, all of which are known predictors of reading success (National Institute for Literacy, 2008; National Reading Panel, 2000). Full details of the programme are provided in [published, 2018]. The current study aimed to investigate whether PrepSTART intervention in the first year of schooling was related to student reading performance 2-year post intervention. We also investigated if there were group differences between students who showed satisfactory reading (accuracy and/or comprehension) performance at the end of year 2 on their emergent literacy and oral language measures immediately post PrepSTART intervention. The following research questions were asked:

(1) Were there differences in student performance between the intervention and business as usual groups on standardised measures of reading accuracy and comprehension at the end of grade 2 ?

(2) Which emergent literacy and/or oral language measures differentiate the "average" and "below average" readers at the end of PrepSTART? 


\section{Method}

Ethics approval was granted by the Human Research Ethics Committee from Griffith University. Approval was also granted by each of the participating school principals and the Assistant Regional Director, Department of Education, Queensland.

\section{Participants}

Students who had participated in the original study (intervention, $n=110$, and business as usual group, $n=27$ ) were provided with consent forms for the longitudinal follow-up (Lennox, Westerveld, \& Trembath, 2018). Following the initial study, consent from 112 participants was received to be included in the longitudinal study, however, eight students were no longer enrolled at their respective schools. Data were collected from 104 participants; however, 15 students were excluded from the current sample as they had incomplete data (13 students with missing time 2 data; 2 students who due to time restraints of testing did not have complete data sets). One student did not wish to participate in testing. Thus, a total of 48 students from the original study did not participate in the longitudinal follow-up and 89 students with written parental consent were included in the follow-up data collection. In summary, attrition across the 3 years of the study equated to $32 \%$ in the intervention group, $44.5 \%$ in the business as usual group.

Participants who were not available for follow-up assessment from the original intervention group $(n=36)$ were compared to participants who continued $(n=74)$ using one-way analysis of variance at the end of the first year of schooling. These groups did not differ based on mean age (months), vocabulary, letter identification (LetterID) or phonological awareness probe, or ethnicity ( $p$-values $>0.05$ ). However, the groups did differ on gender with more girls than boys leaving the study, $X^{2}(1)=4.190, p=.04$.

Similarly, participants unavailable for follow-up in the business as usual group $(n=12)$ were compared at the end of the first year of schooling to participants who continued $(n=15)$. The groups did not differ on measures of mean age (months), ethnicity, gender, vocabulary, LetterID, and phonological awareness probe (all $p$-values $>.05$ ).

A comparison between the student demographics in the intervention and business as usual groups at end of grade 2 was conducted, and the results are presented in Table 1 . As shown, mean age of students was 7:10 (range: 7: 4 to 8:4). There were no significant group differences between the intervention and business as usual groups for age $F(1,89)=0.410$, $p=.523$ or the proportion of males to females $X^{2}=.109, p=.741$ However, the number of

Table 1. Participant details by group (time 2 - end of grade 2).

\begin{tabular}{lccc}
\hline & \multicolumn{2}{c}{ Participants } & \\
\cline { 2 - 3 } Measures & Intervention & Business as usual & Chi-square \\
\hline$n$ & 74 & 15 & \\
Male/female & $38 / 36$ & $7 / 8$ & $p=.741$ \\
Not CALD/CALD & $25 / 49$ & $11 / 4$ & $p=.004^{*}$ \\
Mean age in months (SD) range & $94(3.7)$ & $94(3.6)$ & $p=.523$ \\
& $88-100$ & $89-100$ & \\
\hline
\end{tabular}

CALD: culturally and linguistically diverse students.

${ }^{*}$ A statistically significant group difference. 
students who identified as culturally and linguistically diverse was significantly greater in the intervention group when compared to the business as usual group $\chi^{2}=8.099, p=.004$.

\section{Procedure}

Students were individually assessed at the end of grade 2 by trained graduate-entry speech pathology students who were blind to group membership. To ensure consistency of task administration, a qualified school-based certified practising Speech-Language Pathologist observed the initial administration of the assessment battery and provided feedback accordingly. The test battery (described in methods section), took approximately 45 mins to complete. To ensure a quiet environment, assessments were conducted within empty classrooms and withdrawal rooms. Short breaks were also provided when necessary to minimise student fatigue. All sessions were audio recorded using digital audio recorders. The first author checked test forms for errors in scoring and made adjustments where needed.

\section{Measures}

The measures collected immediately following the 24-week intervention in the first year of schooling were vocabulary (VOCAB), ONQ, oral narrative comprehension (ONC), and LetterID. Further details regarding these measures can be found in Lennox, Westerveld, \& Trembath (2018). A brief summary follows:

Vocabulary (VOCAB) was assessed using an experimental expressive vocabulary task, in which the students were asked to name a picture presented electronically. As per previous research, each of the items were scored as correct or incorrect and a score out of 72 was calculated and used for analysis (Hemsley, Holm, \& Dodd, 2010).

Oral narrative quality (ONQ) was assessed by asking students to retell the story Ana Gets Lost (Swan, 1992), after two exposures. A scoring rubric was used to evaluate each story grammar element that was included as well as overall story coherence. Student responses were scored as $\mathbf{0}, 3$, or 5 marks and a total score out of 40 is calculated. This task has been used in previous research with New Zealand and Australian 4:0 to 7:6-yearold students, including bilingual students (Profile of Oral Narrative Ability, (Westerveld \& Gillon, 2010); (Westerveld \& Vidler, 2016); (Westerveld, 2014). Previous research with using this task with 4-year-old children showed adequate reliability and predictive validity (Westerveld et al., 2012).

Oral narrative comprehension (ONC) was calculated by asking the students to answer eight questions following the first exposure of the story (see above). Each of these responses were scored as correct or incorrect using a scoring rubric ((Westerveld \& Gillon, 2010); (Westerveld et al., 2012); (Westerveld \& Vidler, 2016)).

Letter identification (LetterID) was measured using an experimental task whereby students are asked to point to a letter out of a choice of six. Each item was scored as correct or incorrect and a score out of 18 was calculated and used for analysis (Carson, Gillon, \& Boustead, 2013).

Phonological awareness was also assessed at time 1, using the Sutherland Phonological Awareness Test - Revised (SPAT-R; Neilson, 2003), however was not reported in the initial study. Psychometric properties for the SPAT-R are reported in the manual, demonstrating adequate validity with respect to other tests of phonological awareness, as well as internal consistency and inter-rater reliability (Neilson, 2003). Raw scores were calculated as per the scoring manual and used for analysis. 
At the end of grade 2, students' eading skills were assessed using The York Assessment of Reading for Comprehension (YARC) (Psychological Assessments Australia, 2012). This assessment required students to read two passages out loud and then answer comprehension questions regarding the passage content. Passage Reading assesses both reading accuracy (YRA) and reading comprehension (YRC). The starting passage is selected based on the students' year of schooling as detailed in the test manual. The difficulty of subsequent passages is determined by considering both the number of words read correctly and the number of comprehension questions answered.

The YARC has been standardised on 1049 Australian students aged between 5:1 and 13:3 years. The distribution of the sample across year levels was set at 50 males and 50 females in the Foundation Level (prep) and year 7, and 75 males and 75 females in years 1-6. The YARC was selected as a measure for this study as the norming sample was comprised of an Australian population and includes students from both English and non-English speaking backgrounds, as well as students from a variety of socio-economic backgrounds (Psychological Assessments Australia, 2012). The manual reports moderate to high reliability for reading accuracy and rate. Reading comprehension reliability was assessed using a measure of internal consistency (Cronbach's alpha). Paired passage reliability for reading comprehension ranges between $r=0.63$ and 0.86 .

Using the instructions in the manual, standard scores were calculated for reading accuracy (YRA) and reading comprehension (YRC) measures. Reading accuracy was calculated following the instructions outlined in the manual whereby the number of reading errors from two passages are combined to calculate a reading accuracy raw score. This raw score is converted into a reading ability score and then further into a standard score. Reading comprehension was calculated as the number of questions answered correctly across two passages, first converted to an ability score, then a standard score. For both YRA and YRC, standard scores below 80 were considered "severe" as per the description in the manual; therefore, this cut-off was used as the criteria for "of concern" in the present study.

\section{Results}

\section{Data screening and analysis}

First, data were inspected for distribution. Shapiro-Wilk statistics showed that SPAT-R, ONQ, and YRA as well as YRC were normally distributed. VOCAB, ONC, and LetterID were not normally distributed. A log transformation was performed on VOCAB, as the data were moderately negatively skewed. Log transformations failed to transform LetterID and ONC. Therefore, the original variables retained and raw scores were used in the analyses. For research question one, independent samples $t$-tests were used to compare the intervention group to the business as usual group. Standard scores on YARC reading accuracy (YRA) and YARC reading comprehension (YRC) were the dependent variables (see Table 2). We checked for outliers and none were found. We also checked for homogeneity of variances using the Levene's test. To answer question two, independent $t$-tests (with Bonferroni adjustment for multiple comparisons) were used and adjustment for heterogeneity of variance was made when needed (LetterID). Effect sizes were calculated using Cohen's $d$ and were interpreted as small $(d=.2)$, medium $(d=.5)$, and large $(d=.8)$ (Cohen, 1988). 
Table 2. Reading group performance 2-year post intervention (grade 2).

\begin{tabular}{lccc}
\hline & $\begin{array}{c}\text { Intervention } \\
n=74\end{array}$ & $\begin{array}{c}\text { Business as usual } \\
n=15\end{array}$ & \\
\cline { 2 - 3 } & $\begin{array}{c}\text { Mean (SD) } \\
\text { Range }\end{array}$ & $\begin{array}{c}\text { Mean (Standard Deviation) } \\
\text { Range }\end{array}$ & $\begin{array}{r}\text { Effect size } \\
\text { Cohen's } d\end{array}$ \\
\hline Measures & & & \\
YARC Reading Accuracy & $92.81(15.18)$ & $87.87(11.69)$ & $\mathrm{d}=.36$ \\
YARC Reading Comprehension & $70-124$ & $70-107$ & $\mathrm{~d}=.06$ \\
\hline
\end{tabular}

YARC $=$ York Assessment of Reading Comprehension (Psychological Assessments Australia, 2012). Standard scores reported.

\section{Examining the maintenance of the intervention effect}

We first compared student performance between intervention and business as usual groups on standardised reading measures at the end of the grade 2 . Independent samples $t$-tests did not show statistically significant differences between the intervention and the business as usual groups for any of the reading measures: YRA $t(87)=1.190$, $p=.237, d=.36$; and YRC $t(87)=.198, p=.843, d=.06$, see Table 2 . Given that no significant group differences were found between the groups; student performance was consequently considered as a whole sample (i.e. no distinction between groups).

\section{Group comparisons: average versus below average readers in grade 2}

To answer question two, we compared the "average" and "below average" readers on measures of early literacy at end of the first year of schooling, immediately after the PrepSTART intervention (VOCAB, ONQ, ONC, LetterID, SPAT-R). When comparing students who scored below expectations on the YARC reading accuracy (below SS < 80; as per the manual) to those who scored within the normal range on the YARC (i.e. SS $\geq 80$ ), significant differences were found on measures of LetterID $(d=.69)$ and SPAT-R $(d=1.45)$ with the "average" readers performing significantly better (refer to Table 3 ).

Furthermore, students who performed below expectations on the YARC reading comprehension (below SS $<80$ ) were compared to those who scored within the normal range (i.e. SS $>80$ ) at the end of grade 2, on the first year of schooling measures (VOCAB, ONQ, ONC, LetterID, SPAT-R). After Bonferroni adjustment for multiple comparisons, the "average" readers performed significantly better on all end of first year of schooling measures (refer to Table 4 ), except ONQ $(p=0.03)$, with moderate to large effect sizes.

\section{Discussion}

The aim of this study was to evaluate the long-term reading outcomes of a universal bookbased whole class intervention (PrepSTART) that focused on improving the oral language and emergent literacy skills of students from diverse cultural, linguistic, and economic backgrounds in their first year of schooling. The findings of the initial study indicated that regardless of whether students participated in the PrepSTART programme, all students made significant gains on all measures (Lennox, Westerveld, \& Trembath, 2018). However, the intervention group made significantly more progress on all measures except for LetterID and ONC (Lennox, Westerveld, \& Trembath, 2018). The current study followed the students 
Table 3. Group comparisons on time 1 language and literacy variables of average and below average readers on reading accuracy.

\begin{tabular}{|c|c|c|c|c|c|}
\hline & \multicolumn{5}{|c|}{ Reading accuracy } \\
\hline & $\begin{array}{l}\text { Average Readers } \\
\text { Mean (SD) } \\
\text { Range }\end{array}$ & $\begin{array}{c}\text { Below Average Readers } \\
\text { Mean (SD) } \\
\text { Range }\end{array}$ & $t$ & $p$ & Cohen's $d$ \\
\hline$n$ & 60 & 29 & & & \\
\hline VOCAB & $\begin{array}{c}61.60(6.30) \\
44.0-71.0\end{array}$ & $\begin{array}{c}59.10(6.90) \\
35.0-67.0\end{array}$ & -1.697 & .093 & .37 \\
\hline ONQ & $\begin{array}{c}21.28(9.02) \\
0.0-34.0\end{array}$ & $\begin{array}{c}18.62(8.52) \\
0.0-32.0\end{array}$ & -1.328 & .188 & .30 \\
\hline ONC & $\begin{array}{c}5.08(1.77) \\
0.0-8.0\end{array}$ & $\begin{array}{c}4.51(1.61) \\
1.0-8.0\end{array}$ & -1.448 & .151 & .34 \\
\hline LetterID & $\begin{array}{c}17.03(1.67) \\
10.0-18.0\end{array}$ & $\begin{array}{c}15.17(3.43) \\
5.0-18.0\end{array}$ & -2.765 & .009 & .69 \\
\hline SPAT-R & $\begin{array}{c}33.91(10.73) \\
2.0-52.0\end{array}$ & $\begin{array}{c}18.93(9.82) \\
0.0-38.0\end{array}$ & -6.343 & $<.010$ & 1.45 \\
\hline
\end{tabular}

VOCAB $=$ picture naming task ( $\max$ score $72 ; \mathrm{ONQ}=$ oral narrative quality $(\max$ score 40$) ; \mathrm{ONC}=$ oral narrative comprehension ( $\max$ score 8 ); LetterID = letter identification task (max score 18); SPAT-R = Sutherland Phonological Awareness Test - Revised - raw scores.

Table 4. Group comparisons on time 1 language and literacy variables of average and below average readers on reading comprehension.

\begin{tabular}{|c|c|c|c|c|c|}
\hline & \multicolumn{5}{|c|}{ Reading comprehension } \\
\hline & $\begin{array}{l}\text { Average Readers } \\
\text { Mean (SD) } \\
\text { Range }\end{array}$ & $\begin{array}{c}\text { Below Average Readers } \\
\text { Mean (SD) } \\
\text { Range }\end{array}$ & $t$ & $p$ & Cohen's $d$ \\
\hline$n$ & 51 & 38 & & & \\
\hline VOCAB & $\begin{array}{c}62.92(5.58) \\
44.0-78.0\end{array}$ & $\begin{array}{c}57.92(6.76) \\
35.0-67.0\end{array}$ & -3.814 & $<.01$ & .80 \\
\hline ONQ & $\begin{array}{c}22.17(9.50) \\
0.0-34.0\end{array}$ & $\begin{array}{c}18.05(7.50) \\
0.0-32.0\end{array}$ & -2.209 & .030 & .48 \\
\hline ONC & $\begin{array}{c}5.45(1.61) \\
2.0-8.0\end{array}$ & $\begin{array}{c}4.15(1.63) \\
0.0-7.0\end{array}$ & -3.714 & $<.01$ & .80 \\
\hline LetterlD & $\begin{array}{c}17.11(1.39) \\
12.0-18.0\end{array}$ & $\begin{array}{c}15.50(3.31) \\
5.0-18.0\end{array}$ & -2.825 & .007 & .63 \\
\hline SPAT-R & $\begin{array}{c}35.23(9.00) \\
9.0-52.0\end{array}$ & $\begin{array}{c}20.71(11.89) \\
0.0-47.0\end{array}$ & -6.559 & $<.01$ & 1.37 \\
\hline
\end{tabular}

VOCAB = picture naming task (max score 72$) ; \mathrm{ONQ}=$ Oral narrative quality (max score 40$) ;$ ONC $=$ oral narrative comprehension ( $\max$ score 8 ); LetterID = letter identification task ( $\max$ score 18 ); SPAT-R = Sutherland Phonological Awareness Test - Revised - raw scores.

who had participated in the initial study and aimed to investigate their reading accuracy and comprehension skills at the end of grade 2 (third formal year of schooling).

The first research question evaluated student performance between the intervention and business as usual groups on a standardised measure of reading (accuracy and comprehension) for students at the end of grade 2. As shown in Table 2, there were no differences in student performance between the intervention and business as usual groups 2-year post intervention. One explanation is that the implementation of the PrepSTART intervention influenced teacher practices across all classrooms in the early years of schooling, including those students were originally included in the business as usual group. Although we were able to control instructional practices in our initial study (using a control group design), we had no way of controlling instructional practices in subsequent years, as the teachers regularly changed year groups. Alternatively, similar to 
the study limitations described by Al Otaiba and Fuchs (2006), data were not collected on additional focused or intensive interventions that students may have received during the 2-year post intervention. Future research should collect more detailed information regarding the schools' intervention initiatives, to better understand the students' reading trajectories.

In the current study, when considering the reading performance of both groups combined, students demonstrated low average performance on both RA and RC. However, there was wide variability in performance with some students performing poorly (SS $<70$ ) and others performing in the above average range. These findings are consistent with previous research for students from diverse cultural, linguistic, and economic backgrounds (e.g. Pace, Luo, HirshPasek, \& Michnick Golinkoff, 2017) and indicate that students often perform well below their more advantaged peers on standardised measures of language.

The second question evaluated whether student performance on the end of first year of schooling measures of vocabulary, ONQ, and comprehension, LetterID, and phonological awareness differed between "average" and "below average" readers at the end of grade 2. At the end of grade 2, the groups were divided into "average" and "below average" readers based on their performance on the YARC reading accuracy and reading comprehension measure. As shown in Table 3, students who were identified as "average readers" on reading accuracy on the YARC (SS > 80) at time 2 scored significantly higher on LetterID and SPAT-R at the end of first year of school, with large effect sizes. This finding is consistent with the extensive body of research showing the predictive importance of letter knowledge and phonological awareness to literacy acquisition (e.g. Kendeou, van Den Broek, White, \& Lynch, 2009; National Institute for Literacy, 2008; Oakhill \& Cain, 2012; Simmons et al., 2014). The results of the current study also reinforce the significance of phonological awareness in predicting the reading accuracy performance of students (e.g. Henning et al., 2010; Hogan, Catts, \& Little, 2005; Suggate et al., 2018).

When investigating the performance of students who were identified as "average readers" on reading comprehension measures at end of grade 2 (i.e. SS, 80), the "average readers" performed significantly better on all measures at the end of first year of school (with large effect sizes), except ONC. These findings are consistent with the results reported by Catts, Nielsen, Bridges, and Liu (2014) that indicated measures of oral language predicted reading comprehension over and above word-related reading skills. The results from this study support the usefulness of the experimental vocabulary task that was used in this study (Hemsley et al., 2010) to capture progress following universal oral language and emergent literacy intervention. These results indicate that we need to carefully monitor students who show poor vocabulary skills following intervention. However, as shown in Tables 3 and 4, the ranges in scores suggest that these are not two distinct groups. Therefore, identifying individual students who may be at risk of long-term reading difficulties may not be straightforward. Regardless, it is clear that students who failed to show letter knowledge skills and performed poorly on phonological awareness measures at the end of first year of school, ended up in the "below average" reader group and would have required Tier 2 and/or Tier 3 intervention within an Rtl model.

As shown in Table 4, as a group, children who were reading in the average range scored significantly higher across all preschool precursor literacy measures as well as vocabulary and nonverbal cognition, with large effect sizes, but showed no significant differences in the number of autism symptoms. These findings are consistent with prospective studies with 
children with language disorder (e.g. Murphy et al., 2016) and suggest the early literacy profiles of children with ASD may reflect the children's challenges with language learning more broadly. It should be noted, however, that ranges in scores overlap between the two reader groups, indicating that these two groups were not distinct samples.

\section{Limitations and future directions}

There are several limitations of this study. Firstly, attrition was high, consistent with previous longitudinal follow-up studies (Al Otaiba \& Fuchs, 2006; O'Connor et al., 2009; Wheldall et al., 2016). As described in the original study, group allocation was voluntary and class allocation was non-randomised (Lennox, Westerveld, \& Trembath, 2018). Although the PrepSTART intervention was systematically observed for the intervention classes, this was not the case for the business as usual classes. Student achievement is linked to the quality, type, and amount of instruction received therefore, measures of classroom instruction would assist interpretation of the findings from the current study (Hattie, Taylor, \& Francis, 2012).

Furthermore, we acknowledge that there are a number of factors that impact on learning to read, for example, fluency and working memory which were not monitored in this study (Alonzo, Yeomans-Maldonado, Murphy, \& Bevens, 2016; Lepola, Lynch, Kiuru, Laakkonen, \& Niemi, 2016). There is also considerable research into learning environments, behaviour, and attendance which significantly impact academic skills, however these were not included in the current study (Buckingham et al., 2013; Hay \& Fielding-Barnsley, 2009; Justice, Mashburn, Pence, \& Wiggins, 2008; Tucker-Drob, 2012).

This study focused on three primary schools in an economically disadvantaged, culturally, and linguistically diverse area of Queensland, Australia. A larger scale study, replicating this intervention, would require careful consideration with regards to the inclusion of across-sector educational institutions, stratified levels of socio-economic disadvantage, and teacher variables (e.g. participation, engagement, years of experience). Future research should also consider protective factors for students who are identified as at risk of literacy difficulties, for example, language background, and disability related funding. Finally, these findings should also be considered in relation to parent support and the home learning environment, which have considerable impact on student achievement (Buckingham et al., 2013; Sénéchal \& LeFevre, 2002).

\section{Conclusion}

This study contributes to the evidence regarding the importance of providing universal, highquality, evidence-based early intervention to students at risk of reading difficulties as a way of preventing long term reading difficulties (Simmons et al., 2014; Torgesen, 2000). Although the results from our initial investigation clearly demonstrated the short-term positive effects of the PrepSTART program on students' emergent literacy and oral language outcomes, there were no significant differences on standardised measures of reading accuracy and comprehension two years following the intervention. However, our results replicate international studies that suggest that immediately following intervention positive results are found, but that further intervention is clearly needed for some students to maintain these effects. Therefore, this study emphasises the importance of the need to design, deliver, and monitor evidence-based 
interventions for students who fail to respond to classroom based interventions, specifically those at risk of future oral language and literacy difficulties (Al Otaiba \& Fuchs, 2006).

\section{Acknowledgements}

We wish to acknowledge and thank the co-authors of the PrepSTART programme Tania Kelly (nee Lawrence) and Janice Zee (nee Lee) for their time, commitment, and significant contributions. The authors wish to thank the schools, parents, teachers, teacher aides and Griffith University Master of Speech Pathology students for their commitment to this study. The views expressed in this publication do not necessarily present the views of the Department of Education, Queensland.

\section{Disclosure statement}

No potential conflict of interest was reported by the authors.

\section{ORCID}

Maria Lathouras (D) http://orcid.org/0000-0003-1095-0547

Marleen Westerveld (D) http://orcid.org/0000-0002-5194-2335

David Trembath (D) http://orcid.org/0000-0002-4699-6195

\section{References}

Al Otaiba, S., \& Fuchs, D. (2006). Who are the young children for whom best practices in reading are ineffective? An experimental and longitudinal study. Journal of Learning Disabilities, 39(5), 414-431.

Alonzo, C. N., Yeomans-Maldonado, G., Murphy, K. A., \& Bevens, B. (2016). Predicting second grade listening comprehension using prekindergarten measures. Topics in Language Disorders, 36(4), 312-333.

Australian Curriculum Assessment and Reporting Authority [ACARA]. (2018). The Australian curriculum - English. Retrieved from https://www.australiancuriiculum.edu.au

Bowyer-Crane, C., Snowling, M. J., Duff, F. J., Fieldsend, E., Carroll, J. M., Miles, J., ... Hulme, C. (2008). Improving early language and literacy skills: Differential effects of an oral language versus a phonology with reading intervention. Journal of Child Psychology and Psychiatry, 49(4), 422-432.

Buckingham, J., Wheldall, K., \& Beaman-Wheldall, R. (2013). Why poor children are more likely to become poor readers: The school years. Australian Journal of Education, 57(3), 190-213.

Carson, K. L., Gillon, G. T., \& Boustead, T. M. (2013). Classroom phonological awareness instruction and literacy outcomes in the first year of school. Language, Speech, and Hearing Services in Schools, 44(2), 147-160.

Catts, H. W., Fey, M. E., Zhang, X., \& Tomblin, J. B. (1999). Language basis of reading and reading disabilities: Evidence from a longitudinal investigation. Scientific Studies of Reading, 3(4), 331-361.

Catts, H. W., Hogan, T. P., \& Fey, M. E. (2003). Subgrouping poor readers on the basis of individual differences in reading-related abilities. Journal of Learning Disabilities, 36(2), 151-164.

Catts, H. W., Nielsen, D. C., Bridges, M. S., \& Liu, Y. S. (2014). Early identification of reading comprehension difficulties. Journal of Learning Disabilities, 1-15. doi:10.1177/0022219414556121

Centre For Public Education. (2015). Learning to read, reading to learn: Why third-grade reading is a pivotal year for mastering literacy. Alexandria, VA: National School Boards Association.

Cohen, J. (1988). Statistical power analysis for the behavioral sciences (Vol. 2). Hillsdale, NJ: L. Erlbaum Associates.

Dickinson, D. K., \& Smith, M. W. (1994). Long-term effects of preschool teachers' book readings on lowincome children's vocabulary and story comprehension. Reading Research Quarterly, 29(2), 104. 
Fielding-Barnsley, R., \& Hay, I. (2012). Comparative effectiveness of phonological awareness and oral language intervention for children with low emergent literacy skills. The Australian Journal of Language and Literacy, 35(3), 271-286.

Fricke, S., Bowyer-Crane, C., Haley, A. J., Hulme, C., \& Snowling, M. J. (2013). Efficacy of language intervention in the early years. Journal of Child Psychology and Psychiatry, and Allied Disciplines, 54(3), 280-290.

Gough, P. B., \& Tunmer, W. E. (1986). Decoding, reading, and reading disability. Remedial and Special Education, 7(1), 6-10.

Hattie, J., Taylor, \& Francis. (2012). Visible learning for teachers: Maximizing impact on learning. London, NY: Routledge.

Hay, I., \& Fielding-Barnsley, R. (2009). Competencies that underpin children's transition into early literacy. Australian Journal of Language and Literacy, 32(2), 148-162.

Hempenstall, K. (2009). Research-driven reading assessment: Drilling to the core. Australian Journal of Learning Difficulties, 14(1), 17-52.

Hemsley, G., Holm, A., \& Dodd, B. (2010). Patterns in diversity: Lexical learning in Samoan-English bilingual children. International Journal of Speech-Language Pathology, 12(4), 362-374.

Henning, C., Mclntosh, B., Arnott, W., \& Dodd, B. (2010). Long-term outcome of oral language and phonological awareness intervention with socially disadvantaged preschoolers: The impact on language and literacy. Journal of Research in Reading, 33(3), 231-246.

Hernandez, D. J. (2011). Double Jeopardy: How third-grade reading skills and poverty influence high school education. Baltimore, MD: Annie E. Casey Foundation.

Hogan, T. P., Catts, H. W., \& Little, T. D. (2005). The relationship between phonological awareness and reading: Implications for the assessment of phonological awareness. Language, Speech, and Hearing Services in Schools, 36(4), 285-293.

Justice, L. M., Mashburn, A., Pence, K. L., \& Wiggins, A. (2008). Experimental evaluation of a preschool language curriculum: Influence on children's expressive language skills. Journal of Speech, Language, and Hearing Research, 51(4), 983-1001.

Justice, L. M., McGinty, A. S., Cabell, S. Q., Kilday, C. R., Knighton, K., \& Huffman, G. (2010). Language and literacy curriculum supplement for preschoolers who are academically at risk: A feasibility study. Language, Speech, and Hearing Services in Schools, 41(2), 161-178.

Kendeou, P., van Den Broek, P., White, M. J., \& Lynch, J. S. (2009). Predicting reading comprehension in early elementary School: The independent contributions of oral language and decoding skills. Journal of Educational Psychology, 101(4), 765-778.

Lennox, M., \& Westerveld, M. F. (2014). Enhancing the emergent literacy performance of australian students from disadvantaged backgrounds in their first year of school - A preliminary investigation. Journal of Clinical Practice in Speech-language Pathology, 16(2), 58-65.

Lennox, M, Westerveld, M. F, \& Trembath, D. (2018). Evaluating the effectiveness of PrepSTART for promoting oral language and emergent literacy skills in disadvantaged preparatory students. International Journal of Speech-language Pathology, 20(2), 191-201. doi: 10.1080/ 17549507.2016.1229030

Lepola, J., Lynch, J., Kiuru, N., Laakkonen, E., \& Niemi, P. (2016). Early oral language comprehension, task orientation, and foundational reading skills as predictors of grade 3 reading comprehension. Reading Research Quarterly, 51(4), 373-390.

McIntosh, B., Crosbie, S., Holm, A., Dodd, B., \& Thomas, S. (2007). Enhancing the phonological awareness and language skills of socially disadvantaged preschoolers: An interdisciplinary programme. Child Language Teaching and Therapy, 23(3), 267-286.

Mullis, I. V. S., Martin, M. O., Foy, P., \& Drucker, K. T. (2012). PIRLS 2011 International results in reading. International Association for the Evaluation of Educational Achievement.

Murphy, K. A., Justice, L. M., O'Connell, A. A., Pentimonti, J. M., \& Kaderavek, J. N. (2016). Understanding risk for reading difficulties in children with language impairment. Journal of Speech, Language, and Hearing Research, 59(6), 1436-1447.

Nation, K., Cocksey, J., Taylor, J. S. H., \& Bishop, D. V. M. (2010). A longitudinal investigation of early reading and language skills in children with poor reading comprehension. Journal of Child Psychology and Psychiatry, 51(9), 1031-1039. 
National Institute for Literacy. (2008). Developing early literacy: Report of the national early literacy panel. A scientific synthesis of early literacy development and implications for intervention. (Report).

National Reading Panel. (2000). Teaching children to read: An evidence-based assessment of the scientific research literature on reading and its implications for reading instruction. Washington, DC: US: Government Printing Office.

Neilson, R. (2003). Sutherland Phonological Awareness Test - Revised (SPAT-R). Jamberoo, New South Wales: Acer.

Neumann, M. M. (2016). A socioeconomic comparison of emergent literacy and home literacy in Australian preschoolers. European Early Childhood Education Research Journal, 24(4), 555-566.

O'Connor, M., Arnott, W., McIntosh, B., \& Dodd, B. (2009). Phonological awareness and language intervention in preschoolers from low socio-economic backgrounds: A longitudinal investigation. The British Journal of Developmental Psychology, 27(4), 767-782.

Oakhill, J. V., \& Cain, K. (2012). The precursors of reading ability in young readers: Evidence from a four-year longitudinal study. Scientific Studies of Reading, 16(2), 91-121.

OECD. (2014). PISA 2012 results: What students know and can do - student performance in mathematics, reading and science (Volume I) (Vol. 1). Programme for International Student Assessment. Paris, France: OECD Publishing.

Pace, A., Luo, R., Hirsh-Pasek, K., \& Michnick Golinkoff, R. (2017). Identifying pathways between socioeconomic status and language development. Annual Review of Lingusitics, 3, 285-308.

Parkville Global Advisory. (2014). National evaluation for the low SES national partnership and the literacy and numeracy national partnership - impact stage. Australian Government, Department of Education.

Psychological Assessments Australia. (2012). York Assessment of Reading for Comprehension (YARC) (Australian ed.). Sydney, NSW: GL assessment.

Sénéchal, M., \& LeFevre, J.-A. (2002). Parental involvement in the development of children's reading skill: A five-year longitudinal study. Child Development, 73(2), 445-460.

Serry, T. A., \& Oberklaid, F. (2015). Children with reading problems: Missed opportunities to make a difference. Australian Journal of Education, 59(1), 22-34.

Serry, T. A., Rose, M., \& Liamputtong, P. (2008). Oral language predictors for the at-risk reader: A review. International Journal of Speech-Language Pathology, 10(6), 392-403.

Simmons, D. C., Coyne, M. D., Kwok, O.-M., McDonagh, S., Harn, B. A., \& Kame'enui, E. J. (2008). Indexing response to intervention: A longitudinal study of reading risk from kindergarten through third grade. Journal of Learning Disabilities, 41(2), 158-173.

Simmons, D. C., Taylor, A. B., Oslund, E. L., Simmons, L. E., Coyne, M. D., Little, M. E., ... Kim, M. (2014). Predictors of at-risk kindergarteners' later reading difficulty: Examining learner-byintervention interactions. Reading and Writing, 27(3), 451-479.

Snow, C. E., Burns, M. S., \& Griffin, P. (1998). Preventing reading difficulties in young children. Washington, DC: National Academy Press.

Snow, P. C., Eadie, P. A., Connell, J., Dalheim, B., McCusker, H. J., \& Munro, J. K. (2014). Oral language supports early literacy: A pilot cluster randomized trial in disadvantaged schools. International Journal of Speech-Language Pathology, 16(5), 495-506.

Stanovich, K. E. (1986). Matthew effects in reading: Some consequences of individual differences in the acquisition of literacy. Reading Research Quarterly, 21(4), 360-407.

Storch, S. A., \& Whitehurst, G. J. (2002). Oral language and code-related precursors to reading: Evidence from a longitudinal structural model. Devlopmental Psychology, 38(6), 934-947.

Suggate, S. P. (2016). A meta-analysis of the long-term effects of phonemic awareness, phonics, fluency, and reading comprehension interventions. Journal of Learning Disabilities, 49(1), 77-96.

Suggate, S. P., Schaughency, E., McAnally, H., \& Reese, E. (2018). From infancy to adolescence: The longitudinal links between vocabulary, early literacy skills, oral narrative, and reading comprehension. Cognitive Development, 47, 82-95.

Swan, E. (1992). Ko au na galo (Ana gets lost). Wellington New Zealand: Learning Media, Ministry of Education.

Torgesen, J. K. (2000). Individual differences in response to early interventions in reading: The Lingering problem of treatment resisters. Learning Disabilities Research \& Practice, 15(1), 55-64. 
Torgesen, J. K., Wagner, R. K., Rashotte, C. A., Rose, E., Lindamood, P., Conway, T., \& Garvan, C. (1999). Preventing reading failure in young children with phonological processing disabilities: Group and individual responses to instruction. Journal of Educational Psychology, 91(4), 579-593.

Tucker-Drob, E. M. (2012). Preschools reduce early academic-achievement gaps: A longitudinal twin approach. Psychological Science, 23(3), 310-319.

Tunmer, W. E., \& Chapman, J. W. (2012). The simple view of reading redux: Vocabulary knowledge and the independent components hypothesis. Journal of Learning Disabilities, 45(5), 453-466.

Tunmer, W. E., Chapman, J. W., \& Prochnow, J. E. (2006). Literate cultural capital at school entry predicts later reading achievement: A seven year longitudinal study. New Zealand Journal of Educational Studies, 42(2), 183-204.

Westerveld, M. F., \& Gillon, G. T. (2010). Profiling oral narrative ability in young school-aged children. International Journal of Speech-language Pathology, 12(3), 178-189. doi: 10.3109/ 17549500903194125

Westerveld, M. F., Gillon G. T, \&Boyd, L. (2012). Evaluating the clinical utility of the profile of oral narrative ablility in 4-year-old children. International Journal of Speech-language Pathology, 14(2), 130-140. doi:10.3109/17549507.2011.632025

Westerveld, M. F. (2014). Emergent literacy performance across two languages: Assessing fouryear-old bilingual children. International Journal of Bilingual Education and Bilingualism, 17(5), 526-543. doi:10.1080/13670050.2013.835302

Westerveld, M. F., \& Vidler, K. (2016). Spoken language samples of australian children in conversation, narration and exposition. International Journal of Speech-language Pathology, 18(3), 288298. doi: 10.3109/17549507.2016.1159332

Wheldall, R., Glenn, K., Arakelian, S., Madelaine, A., Reynolds, M., \& Wheldall, K. (2016). Efficacy of an evidence-based literacy preparation program for young children beginning school. Australian Journal of Learning Difficulties, 21(1), 21-39.

Whitehurst, G. J., \& Lonigan, C. J. (1998). Child development and emergent literacy. Child Development, 69(3), 848-872.

Zucker, T. A., Cabell, S. Q., Justice, L. M., Pentimonti, J. M., \& Kaderavek, J. N. (2013). The role of frequent, interactive prekindergarten shared reading in the longitudinal development of language and literacy skills. Developmental Psychology, 49(8), 1425-1439. 